\title{
Atributos microbiológicos de um latossolo sob cultivo de cana-de- açúcar com e sem queima da palhada ${ }^{1}$
}

\section{Microbiological attributes of the soil under cultivation of sugar cane with and without burning straw}

\author{
Francisco Pereira Paredes Junior ${ }^{2}$; Irzo Isaac Rosa Portilho ${ }^{3}$; \\ Fábio Martins Mercante ${ }^{4 *}$
}

\begin{abstract}
Resumo
O objetivo deste trabalho foi avaliar os efeitos do cultivo de cana-de-açúcar sem queima da palhada (colheita mecanizada) em comparação a um sistema com queima da palhada (colheita manual) sobre a biomassa microbiana do solo e índices derivados. O estudo foi conduzido no período de 2009 a 2010, na Usina Dourados, distrito de Itahum, no município de Dourados, MS, num Latossolo Vermelho distrófico, cultivado com cana-de-açúcar em diferentes sistemas. Uma área adjacente, com vegetação nativa, foi incluída no estudo como referencial da condição original do solo. As coletas de solo foram realizadas em três profundidades: $0-5,5-10,10-20 \mathrm{~cm}$, com cinco amostras compostas, oriundas de cinco subamostras, coletadas com intervalo de dez metros entre si, ao longo de um transecto. Considerando os diferentes sistemas de colheita, os resultados demonstraram que o sistema de manejo sem queima da palhada de cana-de-açúcar (colheita mecanizada) favoreceu a manutenção da comunidade de microrganismos do solo, quando comparada ao sistema com queima (colheita manual), especialmente nas camadas mais superficiais do solo. Do mesmo modo, a respiração basal é favorecida pelo manejo sem queima da canade-açúcar, mesmo nas camadas inferiores (até $10-20 \mathrm{~cm}$ ) do perfil do solo.
\end{abstract}

Palavras-chave: Biomassa microbiana, bioindicador, agroecossistemas

\begin{abstract}
This study aimed to evaluate the effects of sugar cane cultivation with and without burning of residues on microbial biomass, soil basal respiration and their derived indices. The study was carried out from 2009 to 2010, at the sugar mills, Itahum district, the city of Dourados, MS, on a Hapludox soil. An adjacent area of native vegetation was included in the study as a reference the original condition of the soil. Soil samples were collected at three depths: 0-5, 5-10, 10-20 cm, with five composite samples, from five subsamples collected at intervals of ten feet between each other, along a transect. Considering the different cropping systems, the results demonstrated the system without burning (mechanized harvesting) of the sugar cane residues, favored microbial biomass and basal respiration and soil chemical properties, compared with the system with burning, especially in the upper layers of soil.

Key words: Microbial biomass, basal respiration, bioindicator, agro-systems
\end{abstract}

\footnotetext{
1 Parte da dissertação de Mestrado do primeiro autor, apresentada ao Programa de Pós-Graduação em Agronomia, Universidade Estadual de Mato Grosso do Sul, UEMS, Aquidauana, MS.

2 Discente, UEMS, Aquidauana, MS. E-mail: franciscoppj@yahoo.com.br

3 Discente de Doutorado em Recursos Naturais, UEMS, Dourados, MS. E-mail: irzo i@terra.com.br

4 Pesquisador, Embrapa Agropecuária Oeste, Dourados, MS. E-mail: fabio.mercante@embrapa.br

* Autor para correspondência
} 


\section{Introdução}

A expansão da cultura da cana-de-açúcar (Saccharum officinarum L.) no cenário agrícola brasileiro tem sido impulsionada por tecnologias que contribuem na conservação do solo, redução de custo de produção e maior produtividade (SCHULTZ et al., 2010). De acordo com o Instituto Brasileiro de Geografia e Estatística (INDICADORES IBGE, 2011), na safra 2010/2011, a área cultivada com a cultura da cana-de-açúcar no Brasil foi de 10,2 milhões de hectares e produção estimada de 722,5 milhões de toneladas, representando um incremento na produção de $7 \%$, em relação à safra anterior (2009/2010). O Estado de Mato Grosso do Sul é responsável por $4,8 \%$ da produção nacional desta cultura, estando em plena ascensão, visto que passou de 265 mil hectares na safra 2009/2010 para 400 mil hectares cultivados na safra 2010/2011 apresentando um crescimento de aproximadamente $34 \%$ na área cultivada. O uso contínuo do solo nesta nova dimensão da produção de cana-deaçúcar tem despertado interesse de pesquisadores no entendimento funcional deste ambiente (BARBOSA, 2010; CORREIA; ALLEONI, 2011).

A queima da palhada, realizada antes da colheita manual, é uma forma de manejo ainda muito utilizada na cultura da cana-de-açúcar, com a premissa de eliminar resíduos vegetais e animais peçonhentos, facilitando o trabalho dos cortadores e do transporte dos toletes para a usina (AZANIA et al., 2006), além de provocar uma queda na população de larva de Diatrea saccharalis e no parasitismo dessas larvas (MACEDO; ARAÚJO, 2000). Entretanto, esta prática pode ocasionar danos nocivos à saúde humana (LOPES; RIBEIRO, 2006), além de um aumento considerável na emissão de gases poluidores e causadores do efeito estufa (FIGUEIREDO; LA SCALA JUNIOR, 2011). Por determinação legal, na maioria dos municípios do Estado de Mato Grosso do Sul, o emprego do fogo está sendo substituído gradualmente pela colheita mecanizada (sem queima), em atendimento ao disposto no Artigo $3^{\circ}$, da Lei Estadual $n^{\circ} 3.404$, de 30 de julho de 2007. Por outro lado, o sistema de manejo de cana crua, sem queima do canavial antes da colheita, tem sido apontado como medida mitigadora do efeito estufa, proporcionando ao solo uma considerável cobertura de resíduo vegetal (palhada), contribuindo para a melhoria da sua qualidade, e, consequentemente, aumentando o potencial produtivo da cultura (TAVARES; LIMA; ZONTA, 2010).

Os processos de colheita (mecanizado e manual) podem causar alterações no ciclo energético, biogeoquímico dos ecossistemas, agregação e atividade biológica do solo (BARBOSA, 2010). Dentre as características biológicas do solo, está presente a biomassa microbiana, definida como a parte viva da matéria orgânica, composta por todos os organismos menores que $5.10^{-3} \mu \mathrm{m}^{3}$, tais como fungos, bactérias, actinomicetos, leveduras e outros componentes da microfauna (GAMARODRIGUES, 1999). Estes microrganismos do solo apresentam respostas rápidas às alterações provocadas pelos sistemas de manejo, em comparação com as mudanças verificadas nas propriedades físicas e químicas, podendo refletir as condições de conservação ou degradação do solo (ARAUJO; MONTEIRO, 2007).

Neste contexto, atributos microbiológicos, como biomassa microbiana e índices derivados (quociente metabólico e microbiano) têm sido propostos para a aferição da qualidade do solo em função das diferentes práticas de manejo adotadas (DORAN; PARKIN, 1994). Assim, estudos envolvendo a biodinâmica do solo em diferentes sistemas de colheita na cultura de cana-de-açúcar podem apontar formas de manejos mais sustentáveis, amenizando consequências ambientais de impactos negativos.

Ante estas informações, o objetivo deste trabalho foi avaliar os efeitos do cultivo de cana-de-açúcar sem queima da palhada (colheita mecanizada), em comparação ao sistema de colheita manual, que envolve a queima da palhada, sobre parâmetros microbiológicos do solo (biomassa microbiana e índices derivados). 


\section{Material e Métodos}

O estudo foi conduzido no período de 2009 a 2010, na Usina Dourados, no Distrito de Itahum, Município de Dourados, MS, num Latossolo Vermelho distrófico, de textura argilosa, situado a $22^{\circ} 01^{\prime} 24,4^{\prime \prime}$ S e $55^{\circ} 08^{\prime} 02^{\prime \prime}$ W, onde o cultivo da cana-de-açúcar, variedade RB925211, representa a principal atividade. O clima da região é classificado como $\mathrm{C}$ wa, mesotérmico úmido, com o verão quente e o inverno seco (FIETZ; FISCH, 2008).

A cultura da cana-de-açúcar foi estabelecida com plantio manual, no ano de 2007, utilizando a variedade RB 925211, espécie caracterizada pela boa brotação, resistência a doenças, maturação precoce e alto teor de sacarose. As avaliações foram realizadas em cultivo sem queima (colheita mecanizada), numa área equivalente a 30,7 ha, e em cultivo com queima (colheita manual), numa área de 5,2 ha. Uma área adjacente, com vegetação nativa (VN) (fragmento de floresta semidecídua), foi incluída no estudo como referencial da condição original do solo.
A primeira avaliação nas áreas de estudo foi realizada em novembro de 2009 (período chuvoso), em ambas as áreas experimentais (com e sem queima). Na área correspondente ao tratamento sem queima, realizou-se a amostragem um mês após o segundo corte da cana crua; na área correspondente ao tratamento com colheita manual, a queima do canavial foi realizada em junho de 2009 , tendo a amostragem de solo ocorrida, portanto, aos quatro meses após a queima da cana. A segunda avaliação no tratamento em que não realizou-se a queima do canavial foi realizada em julho de 2010 (período seco); consequentemente, nove meses após o segundo corte da cana-crua (colheita mecanizada), a amostragem no talhão em que a queima foi realizada ocorreu um mês após a queima da cana, em junho de 2010. Para subsidiar a discussão e o entendimento dos resultados, as precipitações e temperaturas foram registradas durante todo o período experimental (Figura 1).

Figura 1. Variação da temperatura e precipitação total, por decênios, registrada na estação metereológica da Universidade Federal da Grande Dourados (UFGD), distrito de Itahum, município de Dourados, MS.

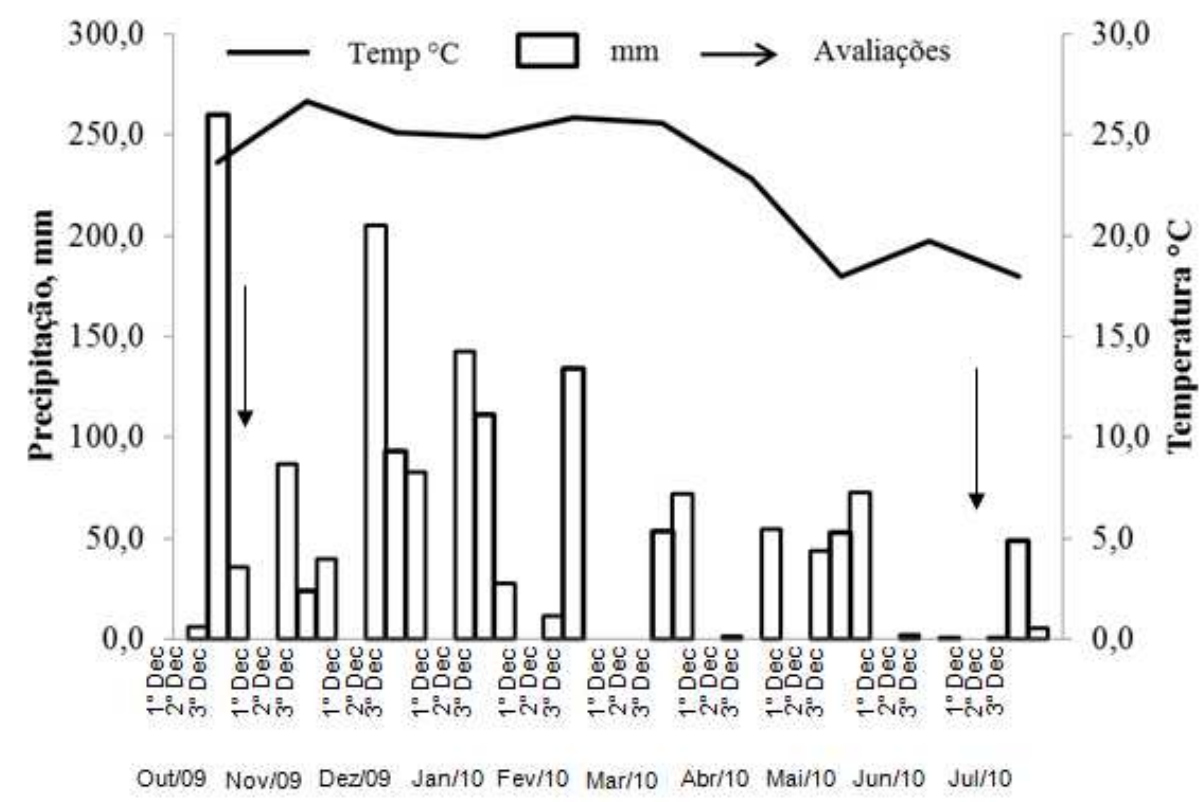

Estação metereológica da Universidade Federal da Grande Dourados, distrito de Itahum, Dourados, MS. Fonte: Elaboração dos autores. 
Em cada sistema, as amostragens foram realizadas em três profundidades (0-5, 5-10 e 10$20 \mathrm{~cm}$ ), com cinco amostras compostas, oriundas de cinco subamostras, coletadas com intervalo de dez metros entre si, ao longo de um transecto. As coletas ocorreram perpendicularmente à linha de plantio, segundo proposto por Nicolodi, Anghinoni e Salet (2002), sendo um dos pontos na linha de plantio e os demais nas entrelinhas. Após a homogeneização, as amostras foram acondicionadas em sacos plásticos e armazenadas em câmara fria $\left(4^{\circ} \mathrm{C}\right)$, durante três dias até a realização das análises laboratoriais. $\mathrm{O}$ solo foi analisado quimicamente, de acordo com Claessen (1997), conforme apresentado na Tabela 1. Para a caracterização química, foi utilizada parte das amostras coletadas para as determinações microbiológicas.

Tabela 1. Atributos químicos do solo nas profundidades de 0-5, 5-10 e 10-20 cm, sob sistemas sem queima (colheita mecanizada), com queima (colheita manual) da cana-de-açúcar e sob vegetação nativa (VN). Valores médios de duas épocas de avaliação. Dourados, MS.

\begin{tabular}{|c|c|c|c|c|c|c|c|c|c|c|c|}
\hline \multirow{2}{*}{ Sistemas } & \multirow{2}{*}{$\begin{array}{c}\text { Prof. } \\
\mathrm{cm}\end{array}$} & pH & $\mathbf{P}$ & $\mathbf{K}$ & $\mathbf{C a}$ & Mg & Al & $\mathbf{H}+\mathbf{A l}$ & SB & CTC & $\mathbf{V}$ \\
\hline & & $\mathrm{H}_{2} \mathrm{O}$ & $\mathrm{mg} / \mathrm{dm}^{3}$ & & \multicolumn{6}{|c|}{------------------ $\mathrm{cmol}_{1} / \mathrm{dcm}^{3}$----------------- } & $\%$ \\
\hline \multirow{3}{*}{ Sem Queima } & $0-5$ & 6,5 & 3,8 & 0,2 & 5,3 & 1,9 & 0,2 & 2,9 & 8,0 & 11,0 & 69,0 \\
\hline & $5-10$ & 6,2 & 2,6 & 0,1 & 4,7 & 1,6 & 0,1 & 3,7 & 6,5 & 10,2 & 61,6 \\
\hline & $10-20$ & 5,8 & 2,5 & 0,1 & 4,2 & 1,4 & 0,1 & 4,7 & 5,0 & 9,7 & 55,4 \\
\hline \multirow{3}{*}{ Com Queima } & $0-5$ & 5,8 & 3,3 & 0,3 & 5,1 & 1,9 & 0,3 & 3,1 & 7,2 & 10,5 & 66,8 \\
\hline & $5-10$ & 5,4 & 2,1 & 0,1 & 4,2 & 1,7 & 0,1 & 3,9 & 5,8 & 9,8 & 58,2 \\
\hline & $10-20$ & 5,1 & 1,3 & 0,1 & 3,0 & 1,3 & 0,1 & 5,0 & 4,4 & 9,4 & 46,6 \\
\hline \multirow{3}{*}{ Vegetação Nativa } & $0-5$ & 5,4 & 2,2 & 0,8 & 4,5 & 2,4 & 0,8 & 9,7 & 5,5 & 15,2 & 52,5 \\
\hline & $5-10$ & 5,1 & 1,0 & 0,6 & 1,8 & 1,4 & 0,6 & 11,7 & 2,8 & 14,6 & 31,8 \\
\hline & $10-20$ & 4,9 & 0,7 & 0,4 & 0,7 & 0,7 & 0,4 & 11,8 & 1,4 & 13,2 & 16,15 \\
\hline
\end{tabular}

Fonte: Elaboração dos autores.

O carbono da biomassa microbiana (C-BMS) foi avaliado pelo método da fumigação-extração, de acordo com Vance, Brookes e Jenkinson (1987). Determinou-se, ainda, a respiração basal $\left(\mathrm{C}-\mathrm{CO}_{2}\right)$, obtida pela incubação das amostras com captura de $\mathrm{CO}_{2}$, em $\mathrm{NaOH}$, durante sete dias, pela adaptação do método da fumigação-incubação, proposto por Jenkinson e Powlson (1976). O C orgânico foi determinado pelo método de Mebius, modificado por Yeomans e Bremner (1988). Após a realização das análises de C-BMS e C- $\mathrm{CO}_{2}$ evoluído, foram determinados os quocientes metabólicos $\left(q \mathrm{CO}_{2}\right)$, conforme Anderson e Domsch (1990), sendo esse atributo obtido, a partir da relação $\mathrm{C}-\mathrm{CO}_{2} / \mathrm{C}-\mathrm{BMS}$, e os quocientes microbianos ( $q \mathrm{MIC}$ ), pela relação C-BMS/ C-orgânico total.

Os resultados foram submetidos à análise de variância e as médias comparadas pelo teste de " $t$ ", a 5\% de probabilidade. O teste de " $\mathrm{t}$ " foi utilizado para estabelecer a comparação estatística entre as amostras (diferentes e independentes), com médias de variáveis quantitativas. As análises estatísticas foram processadas por meio de software Assistat (SILVA; AZEVEDO, 2009).

Os parâmetros referentes à biomassa microbiana, índices derivados e atributos químicos foram submetidos à análise dos componentes principais (ACP). Este método foi adotado por apresentar características de reduzir a multidimensionalidade de conjuntos de dados e gerar eixos interpretáveis (eixos ACP), encontrando combinações lineares das variáveis, de forma a descrever as fontes mais importantes de variação na ordenação dos dados (LEGENDRE; LEGENDRE, 1998). Foram realizadas duas ACPs: parâmetros biológicos/ sistemas de colheita e atributos químicos/ 
sistemas de colheita. As análises dos componentes principais foram realizadas na plataforma $\mathrm{R}(\mathrm{R}$ DEVELOPMENT CORE TEAM, 2005), através do software Vegan (OKSANEN et al., 2006).

Além disso, os parâmetros referentes à biomassa microbiana e índices derivados foram submetidos à análise de agrupamento (cluster analysis), adotando-se o método do vizinho mais distante (complete linkage), a partir da distância euclidiana, para descrever a similaridade entre os sistemas estudados. As análises de grupamento foram processadas por meio do programa Statistica (HILL; LEWICKI, 2007).

\section{Resultados e Discussão}

De acordo com os resultados obtidos (Tabela 2), os teores de C-BMS na vegetação nativa encontram-se situados dentro da faixa de valores verificada num levantamento de diferentes sistemas naturais no Brasil, apresentado por Roscoe et al. (2006). A ausência de preparo do solo, a maior diversidade florística, a manutenção de hifas fúngicas e o acúmulo de serapilheira na superfície do solo contribuem para condições mais favoráveis no sistema sob vegetação nativa (VN), em relação às áreas manejadas com culturas agrícolas anuais ou perenes (MERCANTE et al., 2008).

Dentre os sistemas de manejo avaliados, o tratamento sem queima (colheita mecanizada) da cana-de-açúcar apresentou valores superiores $(\mathrm{p}<0,05)$ para $\mathrm{C}-\mathrm{BMS}$, em relação ao sistema com queima (colheita manual), na profundidade de $0-5$ cm (Tabela 2). Isto evidencia melhores condições de desenvolvimento microbiano no sistema sem queima na camada superficial do solo, refletindo em maior acúmulo de C-BMS. Em relação às demais profundidades, não foram encontradas diferenças significativas entre tais manejos. Estes resultados corroboram com observações de Galdos, Cerri e Cerri et al (2009), que compararam a dinâmica do carbono em solo submetido à queima e não queima da palhada da cana-de-açúcar. Estes autores verificaram que o teor de C-BMS na área sem queima foi 2,5 vezes superior em comparação a área de cana com queima na profundidade $0-10 \mathrm{~cm}$, atribuindo este resultado ao acúmulo de resíduos vegetais e matéria orgânica na superfície do solo, o que favorece o desenvolvimento microbiano. No entanto, Barbosa (2010) não observou diferença significativa para C-BMS entre sistema convencional com e sem queima da palhada nas camadas mais superficiais, porém, verificou uma redução nos teores de C-BMS da camada mais superficial do solo para a camada de maior profundidade, tendência também observada no presente estudo.

O tratamento sem queima da cana-de-açúcar apresentou os maiores valores de respiração basal (evolução de $\mathrm{C}-\mathrm{CO}_{2}$ ), sendo significativamente superior $(p<0,05)$ ao tratamento com queima (Tabela 2). A maior quantidade de resíduos vegetais mantidas na superfície do solo no sistema de colheita sem queima pode ter contribuído com maior fornecimento de energia, nutrientes e aporte de matéria orgânica ao solo, promovendo o aumento da atividade dos microrganismos heterotróficos. Devese salientar que valores mais expressivos de $\mathrm{C}-\mathrm{CO}_{2}$ implicam em uma maior atividade biológica destes microrganismos, que apresentam estreita relação com o C-BMS (VARGAS; SCHOLLES, 2000; FIALHO et al., 2006). Por outro lado, a quantidade dos resíduos vegetais é reduzida quando se efetua a queima, podendo reduzir a dinâmica biológica do solo (CZYCZA, 2009; REDIN et al., 2011). 
Tabela 2. Valores médios de carbono da biomassa microbiana (C-BMS), respiração basal $\left(\mathrm{C}-\mathrm{CO}_{2}\right)$, quociente metabólico $\left(q \mathrm{CO}_{2}\right)$, quociente microbiano $(q \mathrm{MIC})$ e matéria orgânica do solo (MOS) nos sistemas sem queima (colheita mecanizada), com queima (colheita manual) da palhada de cana-de-açúcar e sob vegetação nativa (VN). Médias de duas épocas de avaliação, Dourados, MS.

\begin{tabular}{|c|c|c|c|c|c|}
\hline \multirow[b]{2}{*}{ Sistemas } & C-BMS & $\mathrm{C}-\mathrm{CO}_{2}$ & $q \mathrm{CO}_{2}$ & $q \mathrm{MIC}$ & MOS \\
\hline & $\begin{array}{l}\mu \mathrm{g} \mathrm{C} \mathrm{g}^{-1} \text { solo } \\
\text { seco }\end{array}$ & $\begin{array}{c}\mu \mathrm{g} \mathrm{C}-\mathrm{CO}_{2} \mathrm{~g}^{-1} \text { solo } \\
\mathrm{dia}^{-1}\end{array}$ & $\begin{array}{c}\mu \mathrm{g} \mathrm{C}-\mathrm{CO}_{2} \mu \mathrm{g}^{-1} \\
\mathrm{C}-\mathrm{BMS} \mathrm{h}^{-1}\end{array}$ & $\%$ & $\mathrm{~g} \mathrm{~kg}^{-1}$ \\
\hline & \multicolumn{5}{|c|}{0 a $5 \mathrm{~cm}$} \\
\hline Com queima & $361,66 \mathrm{~b}$ & $14,51 \mathrm{~b}$ & $22,43 \mathrm{a}$ & $1,99 \mathrm{a}$ & $31,64 \mathrm{a}$ \\
\hline Sem queima & 433,43 a & $22,08 \mathrm{a}$ & $20,65 \mathrm{~b}$ & $2,22 \mathrm{a}$ & $33,73 \mathrm{a}$ \\
\hline Vegetação Nativa & 562,59 & 30,67 & 19,81 & 2,32 & 44,36 \\
\hline $\begin{array}{l}\text { Novembro/2009 } \\
\text { Julho/2010 }\end{array}$ & $\begin{array}{l}468,48 \mathrm{a}^{----} \\
326,60 \mathrm{~b}\end{array}$ & $\begin{array}{l}16,00 \mathrm{~b} \\
20,59 \mathrm{a}\end{array}$ & $\begin{array}{c}\text { as de avaliação -- } \\
14,48 \mathrm{~b} \\
28,60 \mathrm{a}\end{array}$ & $\begin{array}{l}2,63 \mathrm{a} \\
1,58 \mathrm{~b}\end{array}$ & $\begin{array}{l}31,16 \mathrm{a} \\
34,21 \mathrm{a}\end{array}$ \\
\hline Julho/2010 & \multicolumn{5}{|c|}{5 a $10 \mathrm{~cm}$} \\
\hline Com queima & $220,84 \mathrm{a}$ & $8,17 \mathrm{~b}$ & $31,03 \mathrm{a}$ & $1,36 \mathrm{a}$ & $29,65 \mathrm{a}$ \\
\hline Sem queima & $217,43 \mathrm{a}$ & 19,13 a & $14,90 \mathrm{~b}$ & $1,57 \mathrm{a}$ & $29,23 \mathrm{a}$ \\
\hline Vegetação Nativa & 368,00 & 32,88 & 41,24 & 1,89 & 33,39 \\
\hline Novembro/2009 & \multicolumn{4}{|c|}{----------------------- Épocas de avaliação -- } & $27,23 \mathrm{a}$ \\
\hline \multirow[t]{2}{*}{ Julho/2010 } & $217,57 \mathrm{a}$ & $14,89 \mathrm{a}$ & $21,40 \mathrm{a}$ & $1,55 \mathrm{a}$ & $31,65 \mathrm{a}$ \\
\hline & \multicolumn{5}{|c|}{10 a $20 \mathrm{~cm}$} \\
\hline Com queima & $179,55 \mathrm{a}$ & $9,20 \mathrm{~b}$ & $24,31 \mathrm{a}$ & $1,11 \mathrm{a}$ & $27,81 \mathrm{a}$ \\
\hline Sem queima & $189,26 \mathrm{a}$ & $11,90 \mathrm{a}$ & $27,10 \mathrm{a}$ & $1,22 \mathrm{a}$ & $25,87 \mathrm{a}$ \\
\hline Vegetação Nativa & 230,26 & 22,85 & 43,32 & 1,49 & 26,33 \\
\hline Novembro/2009 & 255,49 a & $8,13 \mathrm{~b}$ & $\begin{array}{c}\text { as de avaliação - } \\
29,91 \text { a }\end{array}$ & $0,82 \mathrm{~b}$ & $24,38 \mathrm{a}$ \\
\hline Julho/2010 & $113,33 \mathrm{~b}$ & $12,98 \mathrm{a}$ & $21,49 \mathrm{~b}$ & $1,51 \mathrm{a}$ & $29,30 \mathrm{a}$ \\
\hline
\end{tabular}

Médias seguidas de letras diferentes nas colunas contrastam pelo teste de "t", a 5\% de probabilidade.

Fonte: Elaboração dos autores.

O quociente metabólico $\left(q \mathrm{CO}_{2}\right)$ é um índice que expressa a relação entre a respiração basal do solo $\left(\mathrm{C}-\mathrm{CO}_{2}\right)$ e a biomassa microbiana (C-BMS), onde valores elevados são encontrados em condições ambientais estressantes, nas quais a biomassa microbiana necessita de mais carbono para sua manutenção (MENDES et al., 2009). Neste estudo, o sistema com queima apresentou os maiores índices de $q \mathrm{CO}_{2}$ nas duas camadas mais superficiais (0-5 e $5-10 \mathrm{~cm}$ ), sendo significativamente superiores $(\mathrm{p}<0,05)$ àqueles verificados no sistema sem queima. Apenas na profundidade de $10-20 \mathrm{~cm}$ não foram verificadas diferenças significativas $(p<0,05)$ entre os sistemas de cultivo com e sem queima (Tabela 2). Este resultado evidencia uma maior perturbação no ambiente onde a prática da queima foi realizada, principalmente nas camadas mais superficiais. A queima do canavial proporciona um sistema longe do seu estado de equilíbrio e propicia condições de estresse para a biomassa microbiana do solo, resultando em maiores perdas de $\mathrm{CO}_{2}$ e menor incorporação de $\mathrm{C}$ ao seu tecido celular (BARBOSA, 2010). Ao avaliar as propriedades químicas e biológicas de solo de tabuleiro cultivado com cana-de-açúcar com e sem queima da palhada, Mendonza et al. (2000) não verificaram diferença significativa entre os tratamentos, quanto aos valores de quociente metabólico, indicando que a matéria orgânica do solo encontrava-se em níveis estabilizados.

A relação C-BMS/C orgânico total $(q \mathrm{MIC})$ apresentou valores semelhantes $(p>0,05)$ entre os 
diferentes manejos de colheita da cana-de-açúcar, sendo superiores a $1 \%$ em todos os sistemas avaliados (Tabela 2). Estes valores estão de acordo com o proposto por Jenkinson e Ladd (1981), que consideram normal que 1 a $4 \%$ do carbono total do solo corresponda ao componente microbiano. Os índices encontrados neste estudo estão dentro da faixa de valores verificada num levantamento de diferentes sistemas naturais no Brasil, apresentado por Roscoe et al. (2006). O quociente microbiano ( $q \mathrm{MIC}$ ) é um índice utilizado para fornecer indicações sobre a qualidade da matéria orgânica, indicando que sob fatores estressantes para os microrganismos $(\mathrm{pH}$, deficiências nutricionais, presença de metais pesados), a capacidade de utilização do C é menor e, consequentemente, o $q \mathrm{MIC}$ também diminui (WARDLE, 1994).

Entre os sistemas de manejo avaliados, não foi encontrada diferença significativa nos valores de MOS (Tabela 2). De acordo com Rice, Moorman e Beare (1996), a maior parte da matéria orgânica possui frações estáveis e resistentes a alterações, onde mudanças significativas nessas frações podem levar anos ou décadas para serem detectadas. Apesar de não terem sido detectadas alterações em curto prazo, a prática da queima pode reduzir drasticamente os teores de MOS ao longo do tempo, devido ao menor suprimento de resíduos que esta atividade proporciona. A diminuição da cobertura do solo resulta em alterações na temperatura, umidade e aeração, favorecendo assim as perdas de MOS do sistema solo-planta (BAYER; MIELNICZUK, 1999).

Foi observada significância $(\mathrm{p}<0,05)$ na análise de variância, na comparação entre as épocas de amostragens, nas profundidades $0-5$ e $10-20$ $\mathrm{cm}$, para os teores de C-BMS, C- $\mathrm{CO}_{2}, q \mathrm{CO}_{2} \mathrm{e}$ $q \mathrm{MIC}$ (Tabela 2). As variações seguiram um padrão sazonal com maiores valores na estação chuvosa (novembro/2009) e menores na seca (julho/2010). Assim, como observado por Mendonza et al. (2000), o C-BMS e a $\mathrm{C}-\mathrm{CO}_{2}$ apresentaram maiores valores na camada mais superficial $(0-5 \mathrm{~cm})$, sendo esta região como a de maior atividade microbiana no perfil do solo. A baixa precipitação ocorrida próxima a amostragem de julho/2010 pode ter influenciado para a ocorrência de valores elevados de $q \mathrm{CO}_{2}$ na camada de $0-5 \mathrm{~cm}$, refletindo uma maior condição de estresse da biomassa microbiana do solo nesta época.

$\mathrm{Na}$ análise dos componentes principais (ACP), a ordenação dos dados no biplot (Figura 2), com sistemas de colheita em diferentes profundidades do solo, biomassa microbiana do solo e índices derivados, explicou $85 \%$ da variabilidade original, onde $\mathrm{CP} 1$ e $\mathrm{CP} 2$ retiveram $73 \%$ e $12 \%$, respectivamente, das informações originais dos dados. No biplot da Figura 3, os sistemas de colheita, em diferentes profundidades e as variáveis químicas do solo, apresentaram a soma da variabilidade retida nos componentes explicando $89 \%$ da variabilidade original, onde CP1 e CP2 retiveram 70\% e 19\%, respectivamente, das informações originais dos dados.

Pode-se observar no biplot, diferentes posições dos sistemas de colheita sem queima e com queima, nas profundidades 0-5, 5-10 e 10-20 cm (Figuras $2 \mathrm{e}$ 3). A VN, nas primeiras camadas do solo (0-5 e 5-10 $\mathrm{cm}$ ), nas duas épocas de avaliação (novembro/2009 e julho/2010), se agrupa com a maioria dos parâmetros biológicos relacionados à biomassa microbiana do solo, demonstrando ser um ambiente favorável à comunidade microbiana (Figura 2). Estes resultados corroboram a afirmativa de maior equilíbrio e diversidade de fatores nos ecossistemas naturais, podendo atenuar impactos negativos no solo destes ambientes. 
Figura 2. Biplot dos atributos biológicos nos diferentes sistemas de colheita e profundidades do solo, em duas épocas de avaliação. CP1 e CP2 correspondem aos componentes principais. Colheita mecanizada, sem queima (SQ) e manual, com queima (CQ) da palhada de cana-de-açúcar e sob vegetação nativa (VN). * 1.1 profundidade 0-5 cm/novembro/2009, 2.1 profundidade $5-10 \mathrm{~cm} /$ novembro/2009, 3.1 profundidade $10-20 \mathrm{~cm} /$ novembro/2009. 1.2 profundidade $0-5 \mathrm{~cm} / \mathrm{julho} / 2010, \mathbf{2 . 2}$ profundidade $5-10 \mathrm{~cm} / \mathrm{julho} / 2010,3.2$ profundidade $10-20 \mathrm{~cm} / \mathrm{julho} / 2010$.

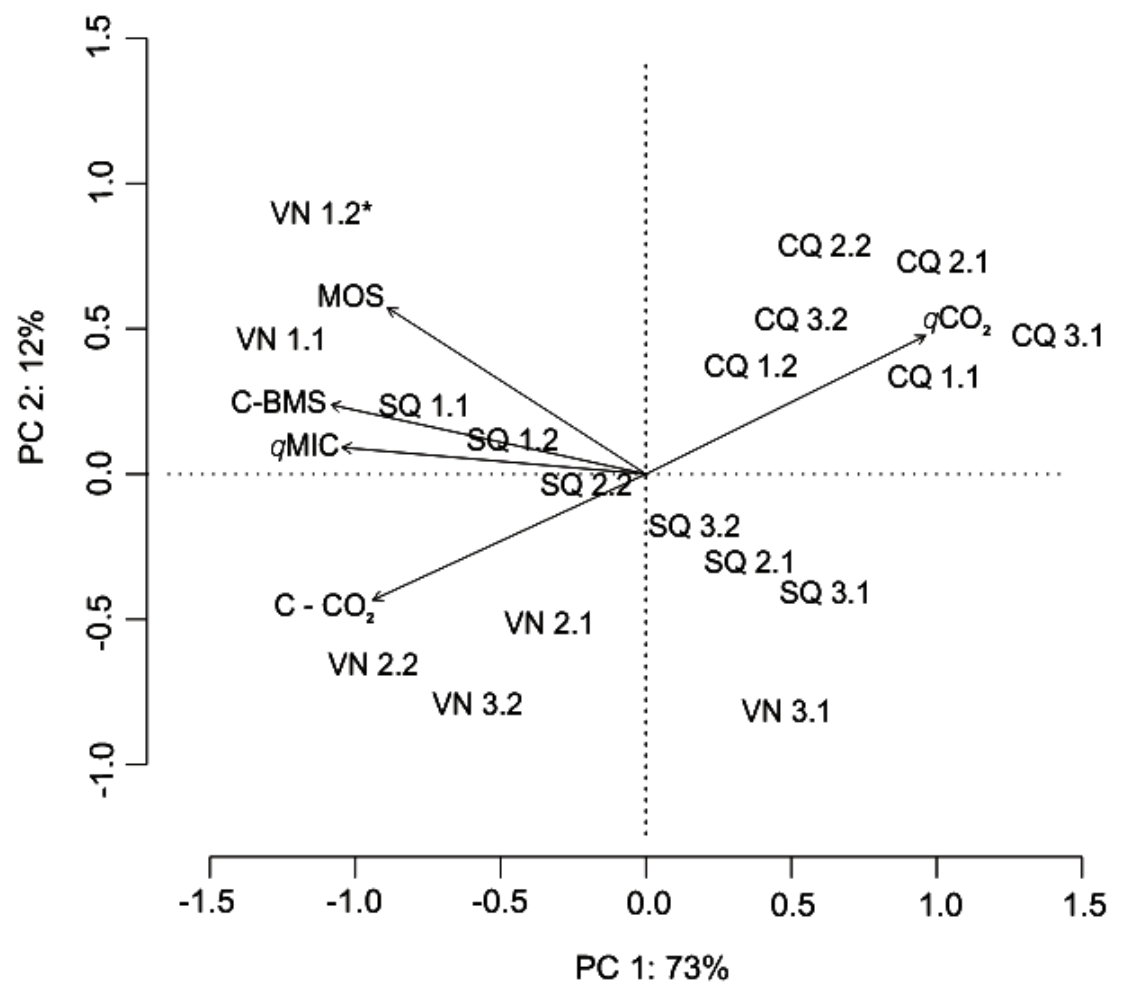

Fonte: Elaboração dos autores.

Entre os sistemas de colheita, a adoção do manejo sem queima da palhada da cana-de-açúcar apresentou tendência próxima à observada para $\mathrm{VN}$, agrupando-se com a maior parte dos parâmetros e índices relacionados à biomassa microbiana do solo, nas camadas mais superficiais do solo e em ambas as épocas de avaliação (Figura 2), proporcionando melhores condições ao desenvolvimento da comunidade microbiana do solo. Mendonza et al. (2000) também verificaram que a presença da palhada da cultura de cana-de-açúcar proporciona condições favoráveis à atividade biológica do solo. Por outro lado, a colheita com queima agrupou-se com o quociente metabólico ( $q \mathrm{CO} 2)$ (Figura 2), mostrando que este sistema apresenta condições ambientais estressantes para as comunidades biológicas do solo.
A ordenação dos dados no biplot das variáveis químicas do solo, pela ACP, mostra a VN nas diferentes profundidades e épocas de avaliação, agrupando-se com as variáveis químicas $\mathrm{K}$, $\mathrm{H}+\mathrm{Al}$, Al e CTC (Figura 3). Estes resultados confirmam a hipótese da presença de alumínio no solo de Florestas Semidecíduas da região e maior capacidade de trocas cationicas (CTC), favorecendo as relações químicas, físicas e biológicas do solo. Entre os sistemas manejados com cana-de-açúcar, a colheita sem queima da palhada agrupou-se com as variáveis químicas $\mathrm{Mg}, \mathrm{Ca}$ e $\mathrm{SB}$ na profundidade de 0-5 cm, em ambas épocas de avaliação (Figura 3). Tais resultados indicam que este sistema torna-se favorável a um maior equilíbrio dos componentes químicos do solo. Segundo Canellas et al. (2003), a preservação da palhada, pela ocasião da colheita 
mecanizada, favorece a adição de matéria orgânica na lavoura de cana-de-açúcar, alterando as propriedades químicas do solo e, proporcionando maior fertilidade. O sistema com queima tornou o solo mais ácido, com menores valores de $\mathrm{pH}$
(Figura 3). Estes resultados sugerem que a colheita com queima da cultura da cana-de-açúcar influencia diretamente a dinâmica do solo, alterando parâmetros biológicos e químicos, que podem indicar distúrbios ou desequilíbrio no ambiente solo.

Figura 3. Biplot das variáveis químicas nos diferentes sistemas de colheita e profundidades do solo, em duas épocas de avaliação. CP1 e CP2 correspondem aos componentes principais. Colheita mecanizada, sem queima (SQ) e manual, com queima (CQ) da palhada de cana-de-açúcar e sob vegetação nativa (VN). * 1.1 profundidade $0-5 \mathrm{~cm} /$ novembro $/ 2009, \mathbf{2 . 1}$ profundidade $5-10 \mathrm{~cm} /$ novembro/2009, $\mathbf{3 . 1}$ profundidade $10-20 \mathrm{~cm} /$ novembro/2009 $\mathbf{1 . 2}$ profundidade $0-5 \mathrm{~cm} / \mathrm{julho} / 2010, \mathbf{2 . 2}$ profundidade $5-10 \mathrm{~cm} / \mathrm{julho} / 2010, \mathbf{3 . 2}$ profundidade $10-20 \mathrm{~cm} / \mathrm{julho} / 2010$.

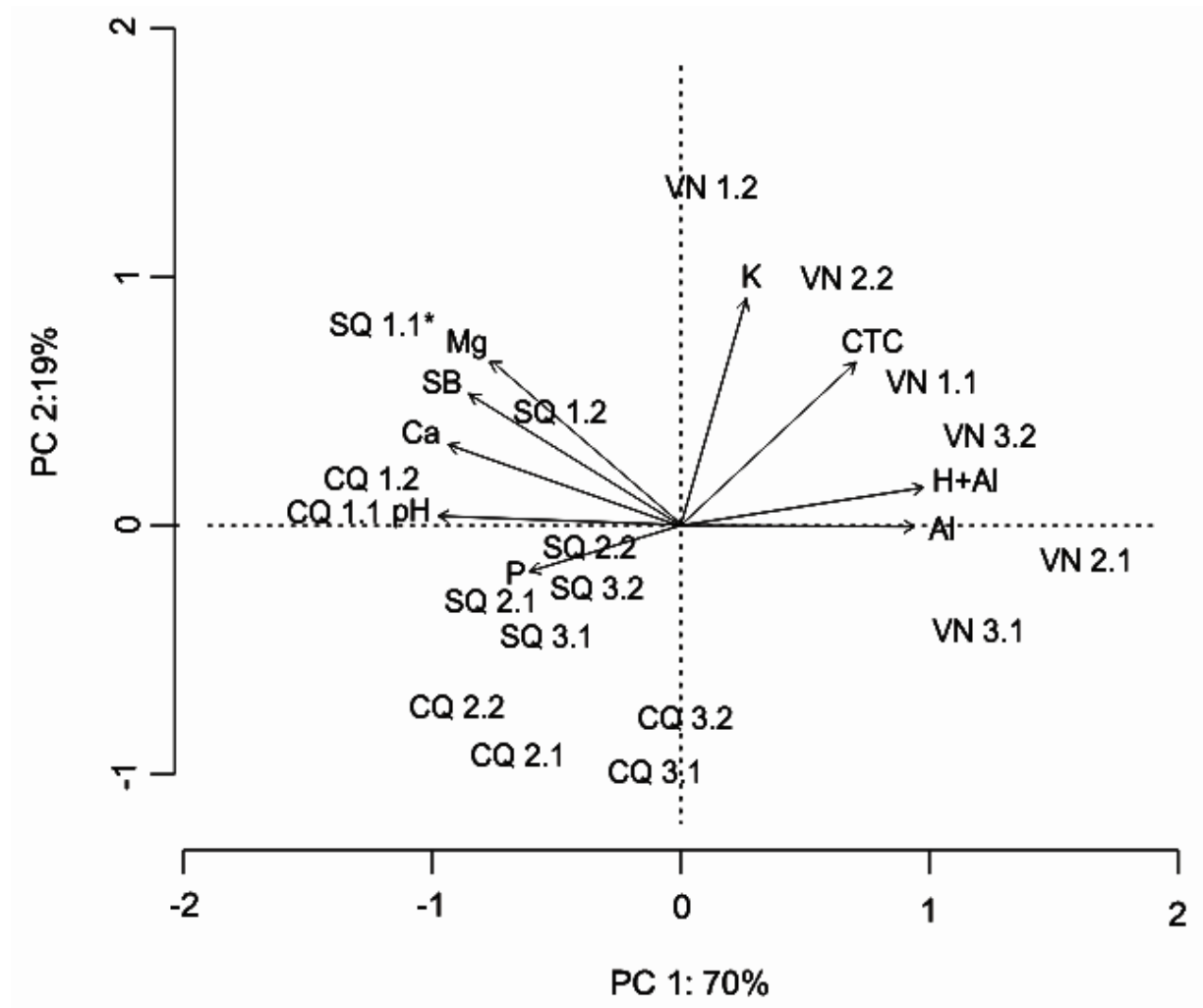

Fonte: Elaboração dos autores.

Em relação à análise de grupamentos, foi possível verificar a formação de dois grupos interpretáveis (A e B) a partir dos dados dos parâmetros da biomassa microbiana do solo e índices derivados (Figura 4). Os grupos compostos pelos sistemas avaliados, a partir da distância euclidiana, apresentaram diferentes similaridades entre si (Figura 4). O grupo "A", composto por VN 1.1, SQ 1.1, VN 2.2, VN 1.2 engloba a ligação com distância inferior a $60 \%$, o que permite inferir que a similaridade entre eles é de $40 \%$ de semelhança entre si. Este grupamento pode ter ocorrido em virtude das características destes sistemas avaliados, que proporcionam maior quantidade de resíduos vegetais na superfície do solo. A presença destes resíduos na superfície do solo, como a palhada da cultura da cana-de-açúcar, proporciona um habitat favorável ao estabelecimento de organismos do solo, como a biomassa microbiana e a macrofauna invertebrada do solo (MENDONZA et al., 2000; 
PORTILHO; PAREDES JUNIOR; MERCANTE, 2011). A decomposição vegetal pode promover a formação de compostos orgânicos, como açúcares, aminoácidos, ceras, fenóis, ligninas e ácidos, fonte de alimento de comunidades biológicas do solo e, consequentemente, contribuir na assimilação de nutrientes pelas plantas, proporcionando maior produtividade das culturas (SOUZA et al., 2005).

Figura 4. Dendrograma de dissimilaridade dos parâmetros da biomassa microbiana do solo, índices derivados nos diferentes sistemas de colheita e profundidades do solo, em duas épocas de avaliação: Colheita mecanizada, sem queima (SQ) e manual, com queima (CQ) da palhada de cana-de-açúcar e sob vegetação nativa (VN). 1.1 profundidade 0-5cm/novembro/2009, 2.1 profundidade $5-10 \mathrm{~cm} /$ novembro/2009, $\mathbf{3 . 1}$ profundidade $10-20 \mathrm{~cm} /$ novembro/2009. 1.2 profundidade $0-5 \mathrm{~cm} / \mathrm{julho} / 2010,2.2$ profundidade $5-10 \mathrm{~cm} / \mathrm{julho} / 2010, \mathbf{3 . 2}$ profundidade $10-20 \mathrm{~cm} / \mathrm{julho} / 2010$. Grupos formados: A e B.

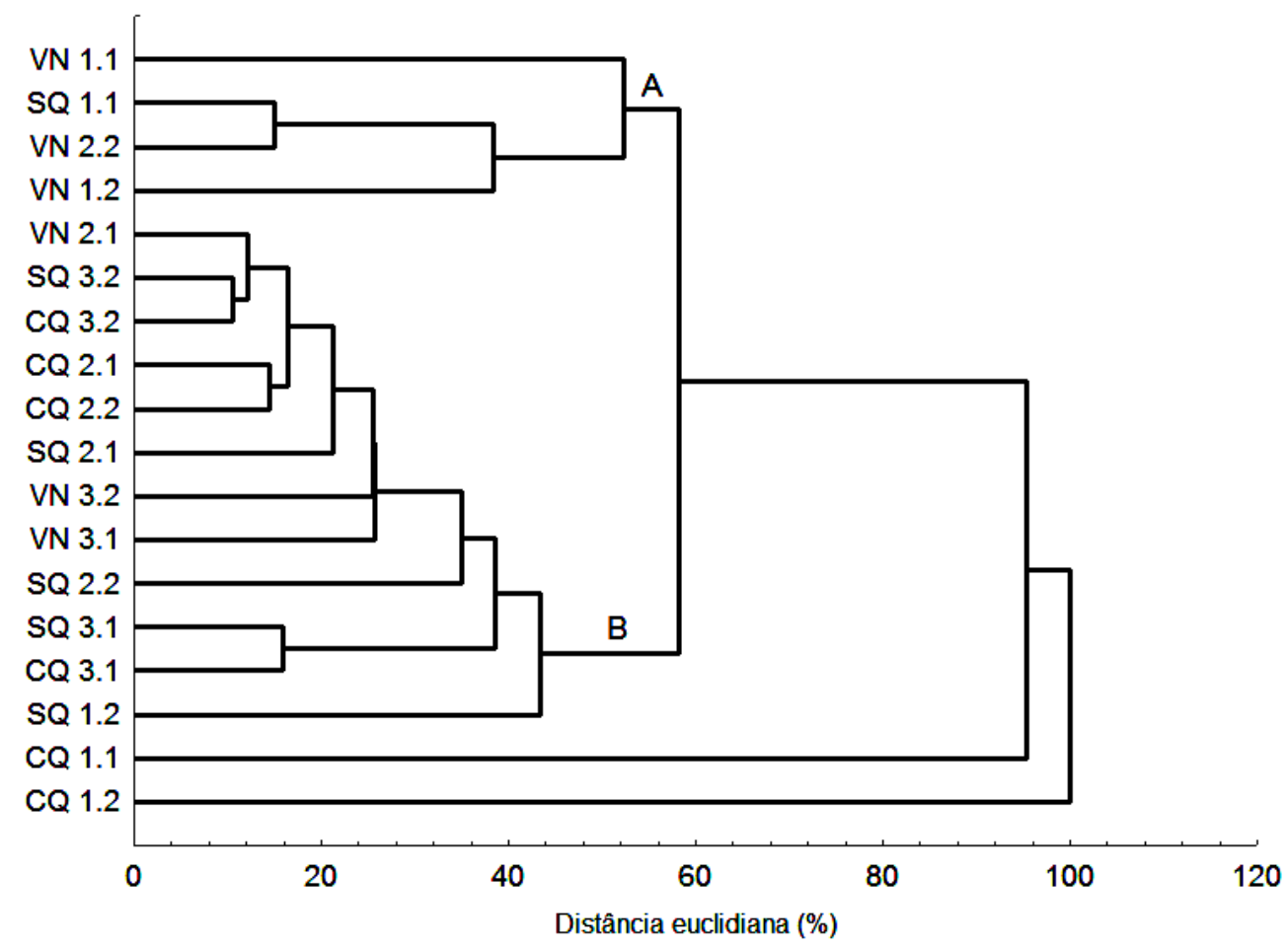

Fonte: Elaboração dos autores.

O grupo "B" apresentou 55\% de semelhança entre si, formado por VN 2.1, SQ 3.2, CQ 3.2, CQ 2.1, CQ 2.2, SQ 2.1, VN 3.1, VN 3.2, SQ 2.2, SQ 3.1, CQ 3.1, SQ 1.2. Este resultado mostra que, nas duas épocas de avaliação, o perfil do solo nas profundidades de 5-10 e 10-20 cm, sob sistema com queima, se agrupa com sistemas sem queima e vegetação nativa (Figura 4), determinando baixa influência do fogo na comunidade microbiana em maiores profundidades do solo. Pode-se visualizar também os sistemas CQ 1.1 e CQ 1.2 isolados dos demais (Figura 4), mostrando o efeito negativo da colheita com queima da palhada da cultura da cana-de-açúcar na comunidade dos microrganismos do solo, na camada $0-5 \mathrm{~cm}$, nas duas épocas de avaliação. Portilho, Paredes Junior e Mercante (2011) também relataram, na mesma área experimental, a interferência negativa da queima da palhada de cana-de-açúcar sobre a diversidade da fauna invertebrada do solo.

Portanto, pode-se inferir que sistemas sem queima da palhada de cana-de-açúcar favorecem 
o equilíbrio dinâmico da biomassa microbiana do solo e, consequentemente, a conservação dos agroecossistemas. Este fato tem sido observado em outros sistemas de manejo com rotação de culturas, que mantém cobertura vegetal na superfície do solo, favorecendo os parâmetros biológicos, químicos e físicos do solo.

\section{Conclusões}

1- A biomassa microbiana do solo, por responder às alterações causadas pelos diferentes sistemas de colheita da cultura da cana-de-açúcar, pode ser considerada um bioindicador em potencial para avaliação da qualidade de solo.

2- O sistema sem queima (colheita mecanizada) da palhada de cana-de-açúcar favorece a manutenção da comunidade de microrganismos do solo, em comparação ao sistema com queima (colheita manual), especialmente nas camadas mais superficiais do solo.

3- Os sistemas de colheita avaliados e profundidades interferem, em geral, nos parâmetros biológicos do solo e atributos químicos.

\section{Agradecimentos}

Fábio Martins Mercante agradece ao CNPq pela bolsa de Produtividade em Pesquisa e Francisco Pereira Paredes Júnior, à FUNDECT, pela bolsa de estudo.

\section{Referências}

ANDERSON, T. H.; DOMSCH, K. H. Application of ecophysiological quotients $\left(q \mathrm{CO}_{2}\right.$ and $\left.q \mathrm{D}\right)$ on microbial biomasses from soils of different cropping histories. Soil Biology and Biochemistry, Oxford, v. 22, n. 2, p. 251255, 1990.

ARAÚJO, A. S. F.; MONTEIRO, R. T. R. Indicadores biológicos de qualidade do solo. Bioscience Journal, Uberlândia, v. 23, n. 3, p. 66-75, 2007.

AZANIA, C. A. M.; AZANIA, A. A. P. M.; PAVANI, M. C. M. D.; ALVES, P. L. C. A. Desenvolvimento da tiririca (Cyperus rotundus) influenciado pela presença e ausência de palha de cana-de-açúcar e herbicidas. Planta Daninha, Viçosa, MG, v. 24, n. 1, p. 29- 35, 2006.

BARBOSA, L. A. Impacto de sistemas de cultivo orgânico e convencional da cana-de-açúcar, nos atributos do solo. 2010. Dissertação (Mestrado em Agronomia) - Universidade de Brasília, Brasília.

BAYER, C.; MIELNICKZUK, J. Dinâmica e função da matéria orgânica. In: SANTOS, G. A.; CAMARGO, F. A. O. (Ed.). Fundamentos da matéria orgânica do solo: ecossistemas tropicais e subtropicais. Porto Alegre: Genesis, 1999. p. 9-26.

CANELLAS, L. P.; VELLOSO, A. C. X.; MARCIANO, C. R.; RAMALHO, J. F. G. P.; RUMJANEK, V. M.; REZENDE, C. E.; SANTOS, G. A. Propriedades químicas de um cambissolo cultivado com cana-de açúcar, com preservação do palhiço e adição de vinhaça por longo tempo. Revista Brasileira de Ciência do Solo, Viçosa, MG, v. 27, n. 5, p. 935-944, 2003.

CLAESSEN, M. E. C. Manual de métodos de análise de solo. 2. ed. rev. atual. Rio de Janeiro: Embrapa-CNPS, 1997. 212 p. (Documentos, 1).

CORREIA, B. L.; ALleONI, L. R. F. Conteúdo de carbono e atributos químicos de Latossolo sob cana-deaçúcar colhida com e sem queima. Pesquisa Agropecuária Brasileira, Brasília, v. 46, n. 8, p. 944-952, 2011.

CZYCZA, R. V. Quantidade e qualidade da matéria orgânica do solo em sistemas de colheita com e sem queima da cana-de-açúcar. 2009. Dissertação (Mestrado em Ciências) - Escola Superior de Agricultura Luiz de Queiroz, Piracicaba.

DORAN, J. W.; PARKIN, T. B. Defining and assessing soil quality. In: DORAN, J. W.; OLEMAN, D. C.; BEZDICEK, D. F.; STEWART, B. A. (Ed.). Defining soil quality for a sustainable environment. Madison: Soil Science Society of America, 1994. p. 107-124. (Special Publication, n. 35).

FIALHO, J. S.; GOMES, V. F. F.; OLIVEIRA, T. S.; SILVA JUNIOR, J. M. T. Indicadores da qualidade do solo em áreas sob vegetação natural e cultivo de bananeiras na Chapada do Apodi - CE. Revista Ciência Agronômica, Fortaleza, v. 37, n. 3, p. 250-257, 2006.

FIETZ, C. R.; FISCH, G. F. O clima na região de Dourados, MS. Dourados: Embrapa Agropecuária Oeste, 2008. 32 p. (Documentos, 92).

FIGUEIREDO, E. B.; LA SCALA JUNIOR, N. Greenhouse gas balance due to conversion of sugarcane áreas from burned to green harverst in Brazil. Agriculture, Ecosystems and Environment, Amsterdam, v. 141, n. 1-2, p. 77-85, 2011. 
GAldos, M. V.; CERRI, C. C.; CERRI, C. E. P. Soil carbon stocks under burned and unburned sugarcane in Brazil. Geoderma, Amsterdam, v. 153, n. 3-4, p. 347352, 2009.

GAMA-RODRIGUES, E. F. Biomassa microbiana e ciclagem de nutrientes. In: SANTOS, G. A.; CAMARGO, F. A. O. (Ed.). Fundamentos da matéria orgânica do solo: ecossistemas tropicais e subtropicais. Porto Alegre: Gênesis, 1999. p. 227-243.

HILL, T.; LEWICKI, P. Statistics methods and applications. Tulsa: StatSoft, 2007. (Eletronic textbook).

INDICADORES IBGE: estatística da produção agrícola: levantamento sistemático produção agrícola, v. 24, 2011. p. 1-82.

JENKINSON, D. S.; POWLSON, D. S. The effects of biocidal treatments on metabolism in soil. V. A method for measuring soil biomass. Soil Biology and Biochemistry, Oxford, v. 8, n. 3, p. 209-213, 1976.

JENKINSON, E. S.; LADD, J. N. Microbial biomass in soil measurement and turnover. In: PAUL, E. A.; LADD, J. N. (Ed.). Soil biochemochemistry. New York: Marcel Dekker, v. 5, 1981. p. 415-471. (Books in soil and the environment).

LEGENDRE, P.; LEGENDRE, L. Numerical ecology. Amsterdam: Elsevier Science, 1998. 853 p.

LOPES, F. S.; RIBEIRO, H. Mapeamento de internações hospitalares por problemas respiratórios e possíveis associações à exposição humana aos produtos da queima da palha de cana-de-açúcar no Estado de São Paulo. Revista Brasileira de Epidemiologia, São Paulo, v. 9, n. 2, p. 215-225, 2006.

MACEDO, N.; ARAÚJO, E. J. R. Efeitos da queima do canavial sobre insetos predadores. Anais da Sociedade Entomológica do Brasil, Araras, v. 29, n. 1, p. 71-77, 2000 .

MENDES, I. C.; HUNGRIA, M.; REIS-JUNIOR, F. B.; FERNANDES, M. F.; CHAER, G. M.; MERCANTE, F. M.; ZILLI, J. E. Bioindicadores para avaliação da qualidade dos solos tropicais: utopia ou realidade? Planaltina: Embrapa Cerrados, 2009. 31 p. (Embrapa Cerrados. Documentos, 246).

MENDONZA, H. N. S.; LIMA, E.; ANJOS, L. H. C.; SILVA, L. A.; CEDDIA, M. B.; ANTUNES, M. V. M. Propriedades químicas e biológicas de solo de tabuleiro cultivado com cana-de-açúcar com e sem queima da palhada. Revista Brasileira de Ciência do Solo, Viçosa, MG, v. 24, n. 1, p. 201-207, 2000.
MERCANTE, F. M.; SILVA, R. F.; FRANCELINO, C. S. F.; CAVAlheiro, J. C. T.; OTSUBO, A. A. Biomassa microbiana em um Argissolo Vermelho, em diferentes coberturas vegetais, em área cultivada com mandioca. Acta Scientiarum: Agronomy, Maringá, v. 34, n. 4, p. 479-485, 2008.

NICOLODI, M.; ANGHINONI, I.; SALET, R. L. Alternativa à coleta de uma secção transversal, com pá de corte, na largura da entrelinha, na amostragem do solo em lavouras com adubação em linha no sistema plantio direto. Revista Plantio Direto, Passo Fundo, n. 69, p. 2228, 2002.

OKSANEN, J.; KINDT, R.; LEGENDRE, P.; O'HARA, B. Community ecology package: vegan. Version 1.8.1. 2006. Available at: <http://cc.oulu. fi/ jarioksa/>. Accessed at: 9 out. 2010.

PORTILHO, I. I. R.; PAREDES JUNIOR, F. P.; MERCANTE, F. M. Efeito da queima da palhada de canade-açúcar sobre a fauna invertebrada epigeica do solo em Mato Grosso do Sul. In: CONGRESSO BRASILEIRO DE CIÊNCIA DO SOLO, 33., 2011, Uberlândia. Anais... Uberlândia: Sociedade Brasileira de Ciências do Solo, 2011. 1 CD-ROM.

R DEVELOPMENT CORE TEAM. $R$ : a language and environment for statistical computing. Vienna: R Foundation for Statistical Computing, 2005. 409 p.

REDIN, M.; SANTOS, G. F.; DENEGA, P. M. G. L.; LUPATINI, M.; DONEDA, A; SOUZA, E. L. Impactos da queima sobre atributos químicos, físicos e biológicos do solo. Ciência Florestal, Santa Maria, v. 21, n. 2, p. 381-392, 2011.

RICE, C. W.; MOORMAN, T. B.; BEARE, M. Role of microbial biomass carbon and nitrogen in soil quality. In: DORAN, J. W.; JONES, A. J. (Ed.). Methods for assessing soil quality. Madison: Soil Science Society of America, 1996. p. 203-216. (Special Publication, 49).

ROSCOE, R.; MERCANTE, F. M.; MENDES, I. C.; REIS JUNIOR, F. B.; SANTOS, J. C. F.; HUNGRIA, M. Biomassa microbiana do solo: fração mais ativa da matéria orgânica. In: ROSCOE, R.; MERCANTE, F. M.; SALTON, J. C. (Ed.). Dinâmica da matéria orgânica do solo em sistemas conservacionistas: modelagem matemática e métodos auxiliares. Dourados: Embrapa Agropecuária Oeste, 2006. p. 163-198.

SCHULTZ, N.; LIMA, E.; PEREIRA, M. G.; ZONTA, E. Efeito residual da adubação de cana planta e da adubação nitrogenada e potássica na cana-soca colhidas com e sem a queima de palhada. Revista Brasileira de Ciência do Solo, Viçosa, MG, v. 34, n. 3, p. 811-820, 2010. 
SILVA, F. A. S.; AZEVEDO, C. A. V. Principal components analysis in the software AssistatStatistical Attendance. In: WORLD CONGRESS ON COMPUTERS IN AGRICULTURE, 7., 2009, Reno.

Proceedings... Reno: American Society of Agricultural and Biological Engineers, 2009. 1 CD-ROM.

SOUZA, Z. M.; PRADO, R. M.; PAIXÃO, A. C. S.; CESARIN, L. G. Sistemas de colheita e manejo da palhada de cana-de-açúcar. Pesquisa Agropecuária Brasileira, Brasília, v. 40, n. 3, p. 271-278, 2005.

TAVARES, O. C. H.; LIMA, E.; ZONTA, E. Crescimento e produtividade da cana planta cultivada em diferentes sistemas de preparo do solo e de colheita. Acta Scientiarum: Agronomy, Maringá, v. 32, n. 1, p. 61-68, 2010.

VANCE, E. D.; BROOKES, P. C.; JENKINSON, D. $\mathrm{S}$. An extraction method for measuring soil microbial biomass C. Soil Biology and Biochemistry, Oxford, v. 19, n. 6, p. 703-707, 1987.
VARGAS, L. K.; SCHOLLES, D. Biomassa microbiana e produção de $\mathrm{C}-\mathrm{CO}_{2}$ e $\mathrm{N}$ mineral de um Podzólico Vermelho Escuro submetido a diferentes sistemas de manejo. Revista Brasileira de Ciência do Solo, Viçosa, MG, v. 24, n. 1, p. 35-42, 2000.

WARDLE, D. A. Metodologia para quantificação da biomassa microbiana do solo. In: HUNGRIA, M.; ARAÚJO, R. S. (Ed.). Manual de métodos empregados em estudos de microbiologia agrícola. Brasília, DF: EMBRAPA-SPI; Goiânia: EMBRAPA-CNPAF, 1994. 542 p. (EMBRAPA-CNPAF. Documentos, 46).

YEOMANS, J. C.; BREMNER, J. M. A rapid and precise method for routine determination of organic carbon in soil. Communications in Soil Science and Plant Analysies, New York, v. 19, n. 13, p. 1467-1476, 1988. 
